\title{
Feasibility of tension braces using Cu-Al-Mn superelastic alloy bars
}

$\operatorname{AUTHOR}(\mathrm{S}):$

Araki, Yoshikazu; Maekawa, Nao; Shrestha, Kshitij C.; Yamakawa, Makoto; Koetaka, Yuji; Omori, Toshihiro; Kainuma, Ryosuke

\section{CITATION:}

Araki, Yoshikazu ... [et al]. Feasibility of tension braces using Cu-Al-Mn superelastic alloy bars. Structural Control and Health Monitoring 2014, 21(10): 1304-1315

\section{ISSUE DATE:}

2014-02-12

URL:

http://hdl.handle.net/2433/198603

\section{RIGHT:}

This is the peer reviewed version of the following article: Araki Y., Maekawa N., Shrestha K. C., Yamakawa M., Koetaka Y. Omori T. and Kainuma R. (2014), Feasibility of tension braces using Cu-Al-Mn superelastic alloy bars, Struct. Control Health Monit., 21: 1304-1315, which has been published in final form at http://dx.doi.org/10.1088/0964-

1726/23/10/105027.; This is not the published version. Please cite only the published version.; この論文は出版社版であ りません。引用の際には出版社版をご確認ご利用ください。 


\title{
Feasibility of tension braces using Cu-Al-Mn superelastic alloy bars
}

\author{
Yoshikazu Araki ${ }^{1, *,}$, Nao Maekawa ${ }^{1}$, Kshitij C. Shrestha ${ }^{1}$, Makoto Yamakawa ${ }^{1}$, Yuji Koetaka ${ }^{1}$, \\ Toshihiro Omori ${ }^{2}$, Ryosuke Kainuma ${ }^{2}$ \\ ${ }^{1}$ Department of Architecture and Architectural Engineering, Kyoto University, Katsura, Nishikyo, Kyoto 615-8540, Japan \\ ${ }^{2}$ Department of Materials Science and Engineering, Tohoku University, Aoba, Sendai 980-8579, Japan
}

\begin{abstract}
SUMMARY
This paper investigates the feasibility of tension braces using $\mathrm{Cu}-\mathrm{Al}-\mathrm{Mn}$ superelastic alloy bars as energy dissipating and self-centering elements for steel frames by performing $1 / 3$ scale shaking table tests. The difficulty with conventional steel tension braces lies in pinching, or significant deterioration of stiffness and strength under cyclic loading. When a steel frame with conventional tension braces is subjected to intense earthquakes, pinching may lead to large residual drift and/or instability. To overcome the difficulty, this paper examines the effectiveness of Cu-Al-Mn superelastic alloy bars, facilitated by their large recovery strain, low material cost, and high machinability, as partial replacement of steel bars in tension braces. In the shaking table tests, a 1/3 scaled 1 bay- 1 story steel frame with the present tension braces is subjected to quasi-static cyclic loading and dynamic harmonic ground motions of $6 \mathrm{~Hz}$. Both the static and dynamic test results demonstrate the effectiveness of the present braces in avoiding pinching under the ductility ratio up to 3. The dynamic test results also demonstrate the capability of the present tension braces in reducing the peak response acceleration within the base shear capacity. To study the rate dependence of the frame response, further, time-history analyses are performed by using a SDOF model based on a uniaxial rate-independent model, calibrated with the quasi-static tests. Comparison of the analytical results with the dynamic test results demonstrates that the rate dependence of the frame response is negligible up to the loading frequency of $6 \mathrm{~Hz}$.
\end{abstract}

KEY WORDS: Cu-Al-Mn; superelastic alloy (SEA); shape memory alloy (SMA); tension-only brace; steel frame; shaking table test

\footnotetext{
*Correspondence to: Yoshikazu Araki, Department of Architecture and Architectural Engineering, Kyoto University, Nishikyo, Kyoto 615-8540, Japan.

†Email: araki@archi.kyoto-u.ac.jp

Contact/grant sponsor: A-STEP program (\#AS2315014C) provided by Japan Science and Technology Agency (JST)

Contact/grant sponsor: The Japan Society of Seismic Isolation
} 


\section{INTRODUCTION}

For low to middle height steel frames, tension braces, composed of thin and long bars and hence sustain only tension, are frequently used due to their advantage in cost and time for construction. It is known however that steel frames with tension braces suffer from pinching. As illustrated in Figure 1(a), no deterioration appears in the restoring force curve at the first cycle. In the second and subsequent cycles, nevertheless, significant deterioration of stiffness and strength appears around the initial position. Pinching is undesirable because it may lead to excessive residual deformation and/or instability of steel frames after strong earthquakes.

A number of studies have been done to propose new tension braces to avoid pinching. These studies can be roughly classified into the following two groups: In one group, mechanical devices were devised to stably dissipate energy by friction or inelasticity [1-4]. In the other group, steel bars were replaced with superelastic alloy (SEA) bars [5-16]. Here, SEA is a class of shape memory alloys that can recover their original shape on unloading at room temperature. The former group of tension braces tends to be more complex than conventional ones. Moreover, since such braces are usually designed to provide a steel frame with bi-linear hysteresis [1-4] as shown in Figure 1(b), it is difficult to avoid large residual deformation when subjected to intense ground motions caused, e.g., by near-fault earthquakes. This also applies to buckling restrained braces $[17,18]$ and zipper frames [19-21], which stably dissipates energy by bi- or tri-linear hysteresis. The second group of braces with SEA bars, on the other hand, is as simple as conventional steel braces, and they can suppress or significantly reduce residual deformations even under intense ground motions. This is because the restoring force curve of a steel frame with SEA tension braces becomes flag shape, where no deformation arises at the unloading state as shown in Figure 1(c). The flag-shape hysteresis is effective to resolve the problems associated with pinching mentioned above by providing steel frames with self-centering capability. Recent advances in use of negative stiffness device [22, 23] also aims at providing self-centering capability with steel frames without using special materials.

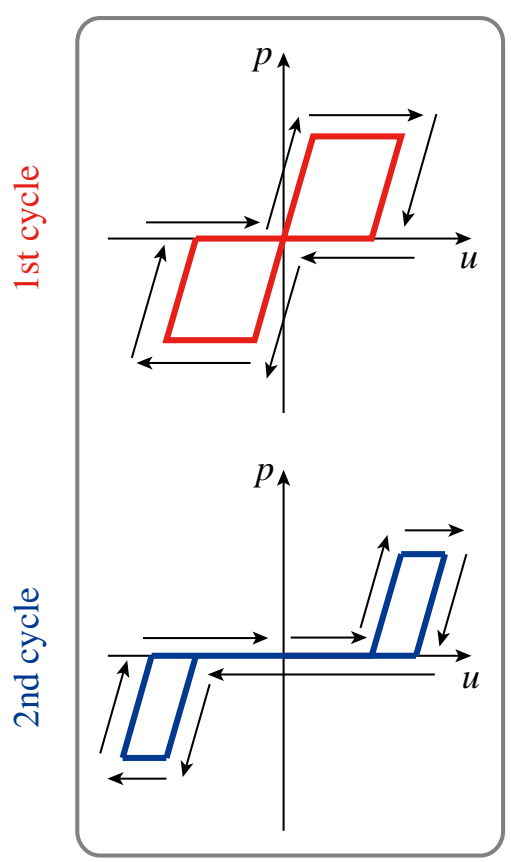

(a)

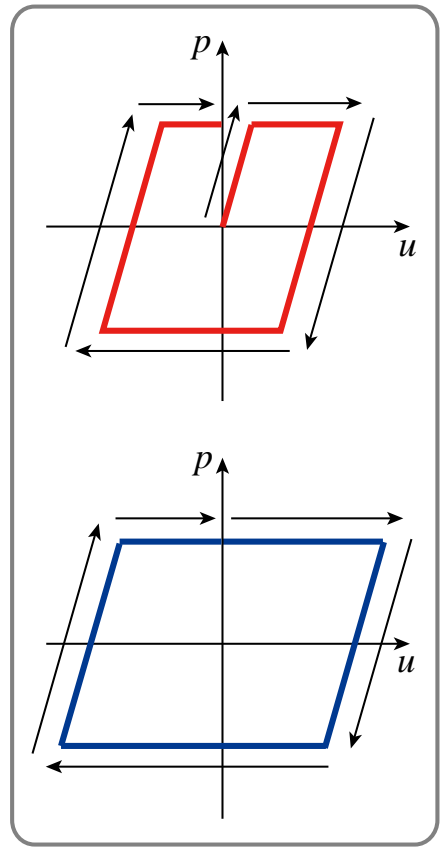

(b)

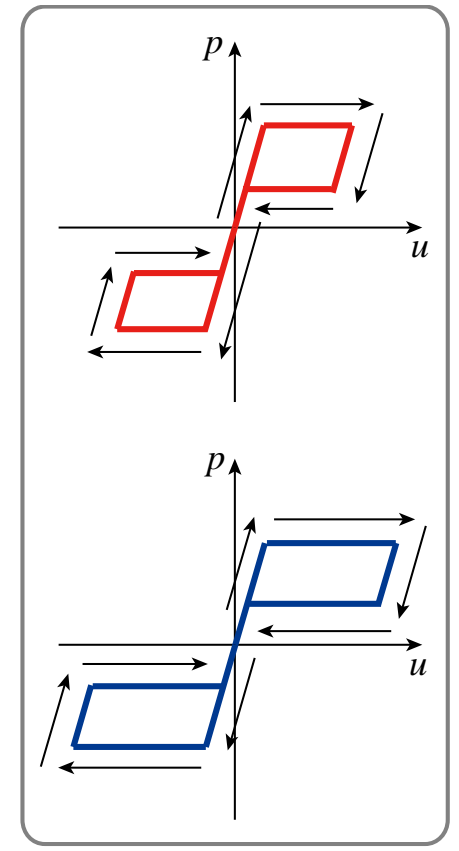

(c)

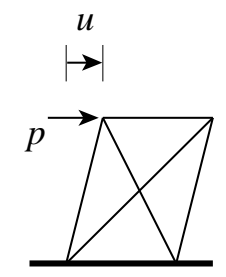

Figure 1. Restoring force curves: (a) Pinching, (b) Bi-linear, and (c) Flag-shape. 
The present paper concerns application of SEAs to tension braces. Application of SEA bars as energy dissipating and self-centering elements, widely in the form of tension braces in steel frames, has been reported by many researchers. Dynamic experimental works were performed by Dolce et al. [5], Casciati and Faravelli [11], Torra et al. [12] and Carreras et al. [13] on SEA bars as energy dissipative tension brace systems in steel frame structures. Miller et al. [16] performed quasi-static cyclic tests on Ni-Ti SEA self-centering buckling restrained brace where the brace system would work also in compression. Additionally, extensive numerical works [6-10,14-15] have been done to study the implementation of SEA braces for passive control of structures subjected to seismic excitations. In most of the works, Ni-Ti SEAs were used because of their superior mechanical properties to other SEAs. Nevertheless, high material cost and machining difficulty of Ni-Ti SEAs limit their extensive use in practical applications. Although the use of Cu-based SEAs has been studied in Casciati and Faravelli [11] and Carreras et al. [13] to overcome the difficulties of Ni-Ti SEAs, it is reported that their mechanical properties are comparatively inferior to Ni-Ti SEAs except the case of single crystals. Cu-Al-Be SEAs are reported to have superelastic strain about $4 \%$ [24], which is half of that of Ni-Ti. Furthermore, NiTi SEAs are also reported to have relatively large rate dependence [25-27], non-negligible in the design of seismic devices.

The objective of this paper is to examine the feasibility of tension braces using Cu-Al-Mn SEA bars as energy dissipating and self-centering elements. These newly developed Cu-Al-Mn SEA bars offer excellent superelasticity with superelastic strain exceeding 8\% [28-30], superior machinability, and cost effectiveness, compared to more popular Ni-Ti SEAs. Here, quasi-static and dynamic tests of reduced scale steel frames are performed using a shaking table. Through the tests, this paper attempts to demonstrate that pinching can be effectively avoided by the present tension braces. Furthermore, this paper examines the rate dependence of the frame response. In Reference [27], it has been demonstrated that the rate dependence of $\mathrm{Cu}-\mathrm{Al}-\mathrm{Mn}$ SEAs on mechanical properties is negligible up to the loading rate of $1 \mathrm{~Hz}$, comparatively superior to Ni-Ti SEAs. Since the vibration of steel frames under earthquake ground motions usually includes frequency components higher than $1 \mathrm{~Hz}$, it is important to examine the rate dependence of Cu-Al-Mn SEAs at higher loading frequencies, e.g. more than $5 \mathrm{~Hz}$. Nevertheless, it is often difficult to apply large inelastic deformation at such a frequency range due to limitations of loading machine's capacity. This paper attempts to overcome the limitation by effective use of resonance. In the shaking table tests, a 1/3 scaled 1 bay- 1 story steel frame with the present tension braces is subjected to quasi-static cyclic loading and dynamic harmonic loading of $6 \mathrm{~Hz}$. A uniaxial rate independent hysteretic model is adopted for the numerical study to simulate the response of SEA hysteresis based on the identified mathematical parameters. Furthermore, to study the rate dependence of the frame response, time-history analyses are performed by using a SDOF (single degree of freedom) model calibrated with the quasi-static tests, and the analytical results are compared with the dynamic test results.

\section{TEST SETUP}

\subsection{Steel frame}

Figure 2(a) illustrates a schematic view of a 1/3 scaled 1 bay- 1 story steel frame specimen. In Figure 2(a), the solid (blue) lines show the present tension steel braces with SEA bars, and the dotted (gray) lines indicate conventional steel members. As shown in Figure 2(b), steel plate mass of 350kg and $1200 \mathrm{~mm} \times 450 \mathrm{~mm} \times 80 \mathrm{~mm}$ is attached to the top of the frame specimen. The frame specimen is designed so that deformation takes place only in X-direction and no deformation is allowed in 
Y-direction. The grade of the steel members is Japanese Industry Standard SS400, whose nominal tensile strength is $400 \mathrm{MPa}$. In X-direction, all the connections are pin-jointed and have no moment resistance. The columns have unequal angle sections $125 \mathrm{~mm} \times 75 \mathrm{~mm} \times 7 \mathrm{~mm}$. The beams in $\mathrm{X}$ direction have rectangular section of $40 \mathrm{~mm} \times 27 \mathrm{~mm}$, and those in $\mathrm{Y}$ direction have angle section of $75 \mathrm{~mm} \times 75 \mathrm{~mm} \times 6 \mathrm{~mm}$. The braces in $\mathrm{Y}$ direction have rectangular section of $32 \mathrm{~mm} \times 6 \mathrm{~mm}$. The details of the braces in $\mathrm{X}$ direction are given in the next subsection. All the members except the SEA bars are designed so that they are in the elastic range during the static and dynamic tests.

\subsection{Tension brace}

As shown in Figure 3, the top portion of a tension brace is an SEA bar of 8mm diameter and the remaining is a steel bar of $12 \mathrm{~mm}$ diameter. Figure 3(a) shows that the bottom of the steel bar is connected to the shaking table. And as shown in Figure 3(b), the top of the steel bar is connected to the SEA bar, and the top of the SEA bar is connected to the beam of the steel frame. Since the brace has 3 pin bearings, it works only in tension. The length of the SEA bar is $150 \mathrm{~mm}$. The SEA bar has the central portion of $110 \mathrm{~mm}$ length with reduced diameter of $4 \mathrm{~mm}$, and the both ends $(20 \mathrm{~mm}$ in length) are threaded. These larger diameter threading ensures that the threaded portions remain linearly elastic during the loading process.

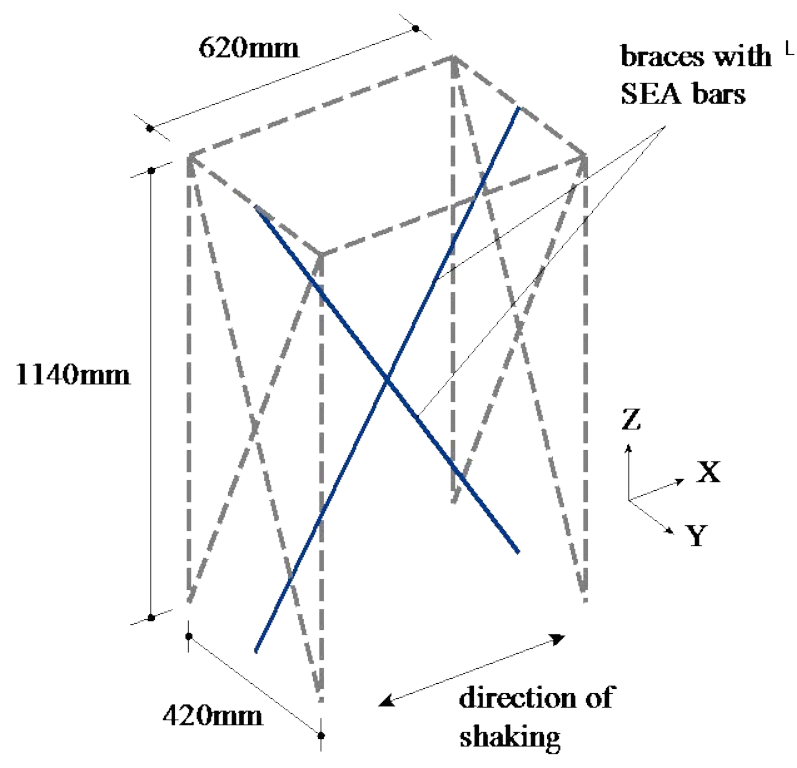

(a)

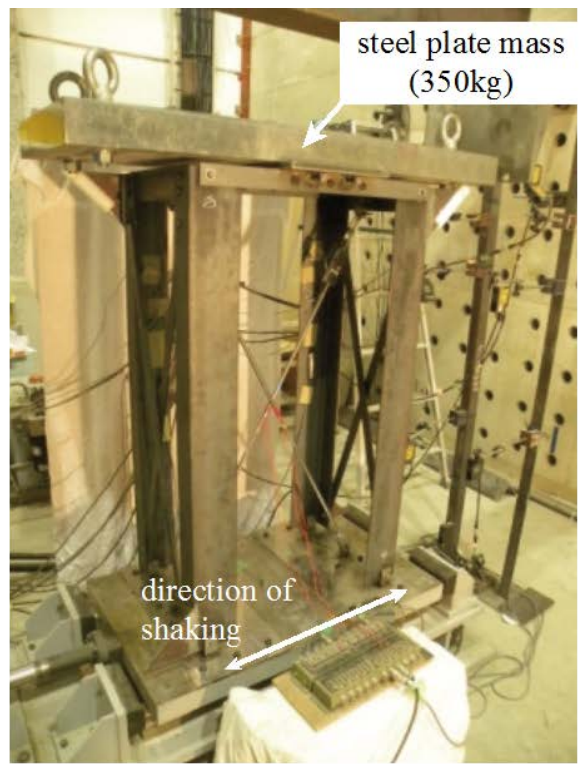

(b)

Figure 2. The steel frame specimen: (a) Schematic view, and (b) Photograph. 


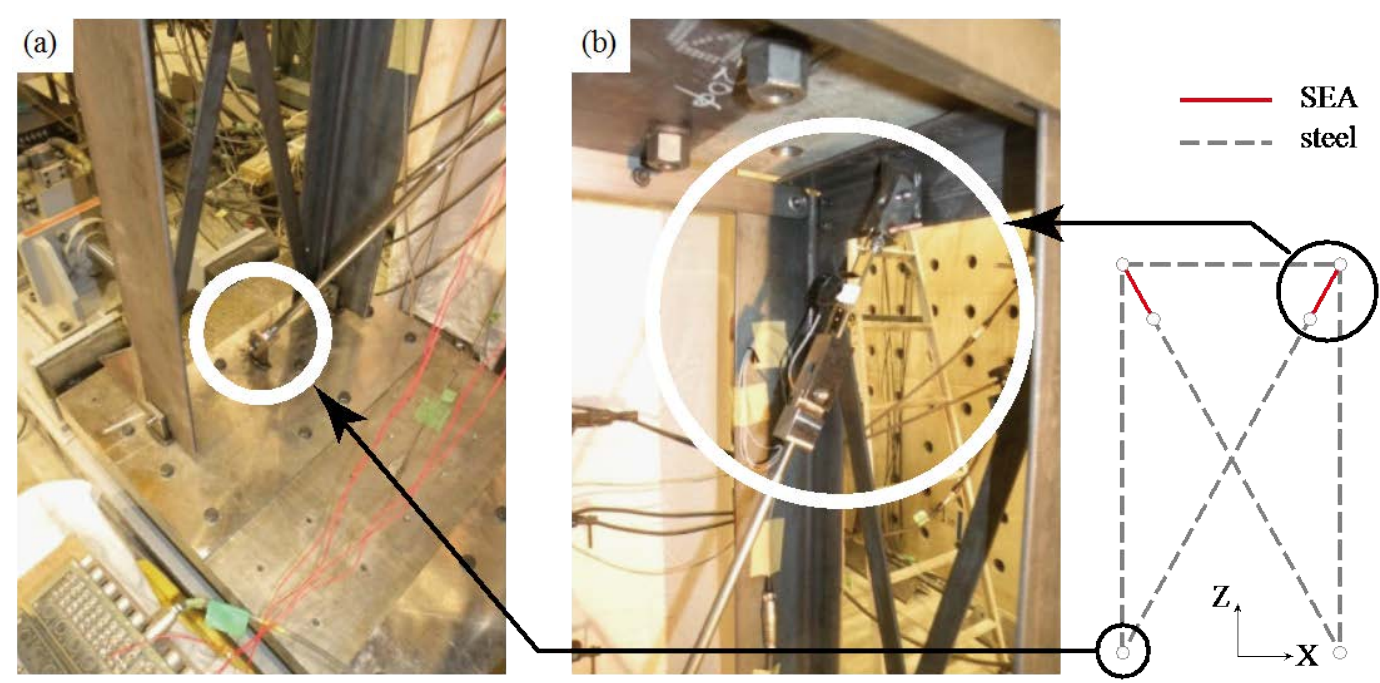

Figure 3. Details of the pin joints in a tension brace: (a) bottom pin joints, and (b) top pin joints.
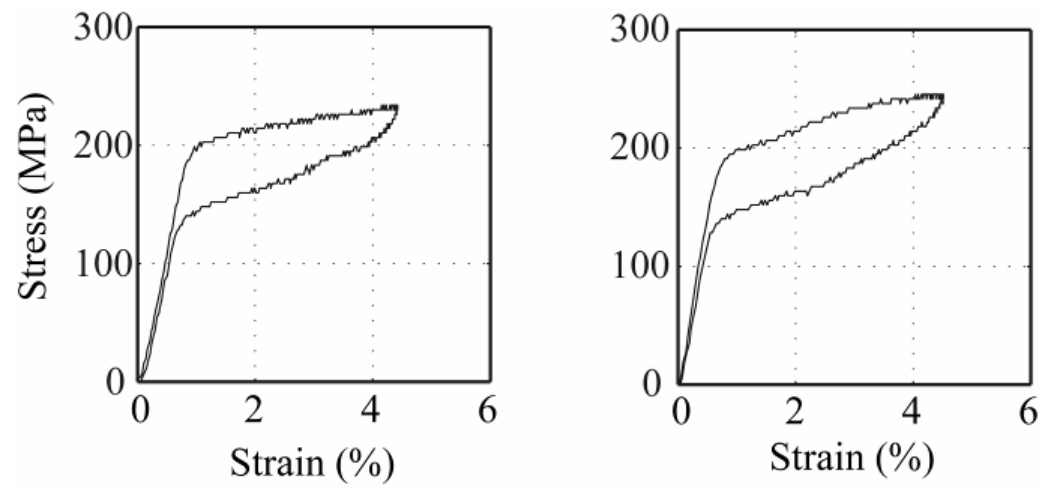

Figure 4. Results of preliminary cyclic loading tests on SEA bars.

Cu-Al-Mn SEA bars, prepared by Furukawa Techno Material Co., Ltd, have material composition with $\mathrm{Cu}-16.7$ at.\%Al-11.6 at.\%Mn. The SEA bars were obtained by hot forging and cold drawing. The solution treatment was conducted at $900{ }^{\circ} \mathrm{C}$, followed by quenching in water, and they were subsequently aged at $200^{\circ} \mathrm{C}$ to stabilize superelastic property. The martensite start temperature $M_{\mathrm{s}}$, the martensite finish temperature $M_{\mathrm{f}}$, the austenite start temperature $A_{\mathrm{s}}$, and the austenite finish temperature $A_{\mathrm{f}}$ of above bars are, $M_{\mathrm{s}}=-74^{\circ} \mathrm{C}, M_{\mathrm{f}}=-91^{\circ} \mathrm{C}, A_{\mathrm{s}}=-54^{\circ} \mathrm{C}$, and $A_{\mathrm{f}}=-39^{\circ} \mathrm{C}$. The SEA bars are pre-trained up to strain of over $4 \%$. Stress-strain curve of each SEA bar under quasi-static cyclic loading (sinusoidal load of $0.001 \mathrm{~Hz}$ frequency) is shown in Figure 4 . The yield, or the forward transformation stresses of the tested SEA bars are in the range between 190 and 200MPa. Young's modulus for the SEA bars is around $25 \mathrm{GPa}$, which is relatively small because the strain was calculated using the relative displacement between the connectors. 


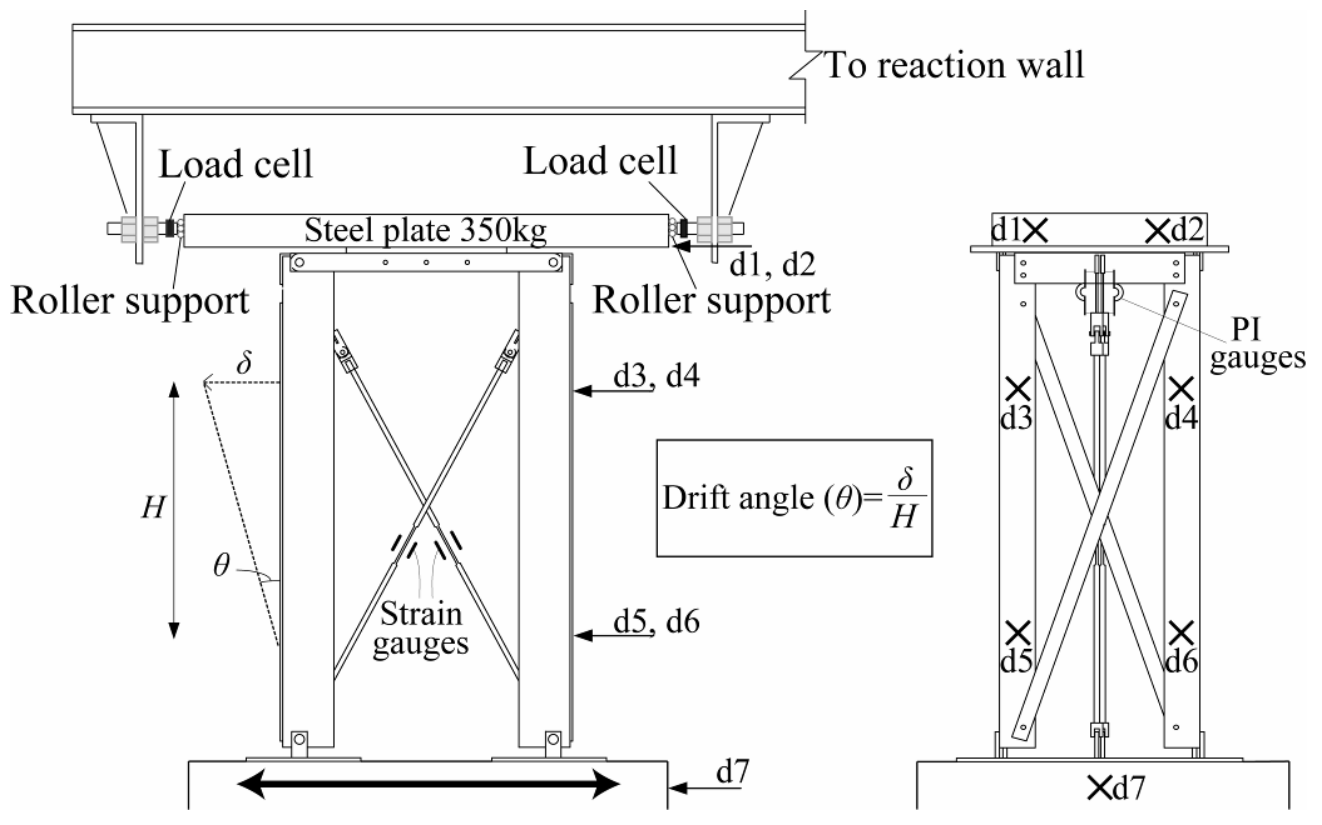

Figure 5. Static test set-up.

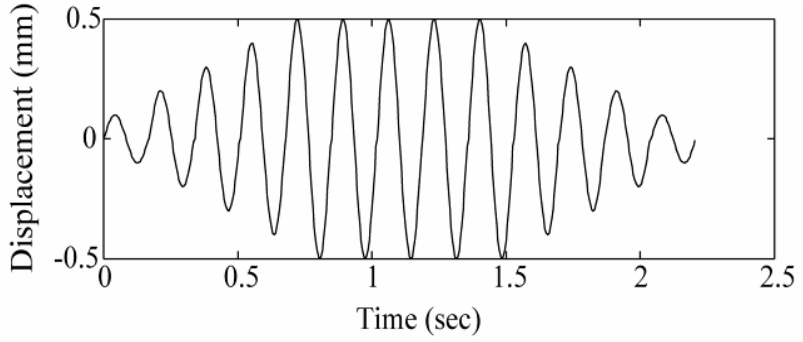

(a)

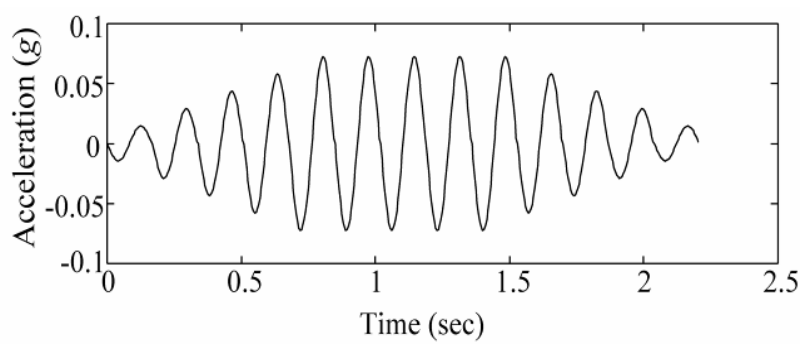

(b)

Figure 6. Time histories of base ground motion RUN1: (a) displacement, and (b) acceleration.

\subsection{Loading and measurement conditions}

2.3.1 Quasi-static test. Figure 5 shows the test setup for the quasi-static test. A quasi-static cyclic load is applied using a hydraulic shaking table, while the top of the steel frame is fixed to the reaction wall using a reaction beam. Two roller supports are provided at both sides of the top steel plate mass as shown in Figure 5. The supports allow vertical translation of the steel plate but do not allow horizontal translation. Prior to loading, both the braces are pre-tensioned up to $0.01 \%$ strain, to keep the frame stiff and stable. Displacement controlled sinusoidal load, with the target amplitude of drift angle equal to $1 / 100$ radian at the frequency of $0.005 \mathrm{~Hz}$, is given for 3 cycles by the shaking table. Load measurements are recorded using two load cells located at both sides of the roller supports. Non-contact laser displacement transducers are used to acquire the displacement records at points d1 to d7, whose locations are shown in Figure 5. As shown in Figure 5, strain gauges are attached to the reduced section of $12 \mathrm{~mm}$ diameter steel bars to measure the axial force of the braces. Clip-type displacement transducers (PI-gauges) are used to measure the elongation of the SEA bars.

2.3.2 Dynamic test. The only difference from the test up of the quasi-static test shown in Figure 5 is the removal of the reaction beam. Displacement and strain measurements are made in the same way as in the quasi-static test. In the dynamic test, accelerometers are attached to the shaking table and 
the top of the steel plate mass. The sampling rate for all the measurements is $5000 \mathrm{~Hz}$. Pre-tensioning of both the braces is done prior to loading similar to the static test. A sequence of ground motions are applied to the steel frame. Total 8 runs of sinusoidal ground motions are applied with the peak ground displacements (PGDs) of 0.5mm (RUN1), 1.0mm (RUN2), 1.5mm (RUN3), 2.0mm (RUN4), 2.5mm (RUN5), 3.0mm (RUN6), 3.5mm (RUN7), and 4.0mm (RUN8). As an example of such ground motions, Figure 6 illustrates the time histories of the ground motion at the PGD 0.5mm (RUN 1).

The value of the natural period for the tested brace frame, obtained from the stiffness value recorded during the static test, reported later in Section 4.1, is around $6 \mathrm{~Hz}$. In order to cause large inelastic deformation in the tested frame at higher frequency range, within the limited capacity of the shaking table, here, the frequency of sinusoidal ground motion is set to $6 \mathrm{~Hz}$, effectively using resonance to cause large deformation at a high frequency rate.

\section{NUMERICAL SIMULATIONS}

\subsection{Constitutive modeling of SEAs}

Extensive works have been done with comprehensive constitutive laws for shape memory alloys in a thermodynamic formulation proposed by Tanaka [31], Achenbach [32] and Liang and Rogers [33]. Additional details can be found in Lagoudas [34]. Such models are relatively complicated and involve parameters governing the shape-memory effect. The present study is on shape memory alloy in pseudoelastic regime or SEA, and can hence be modeled by a relatively simple model, like the one proposed by Graesser and Cozzarelli [35]. Additionally, one of the primary objectives of numerical study is to check whether structure's response to dynamic high frequency loading can be modeled based on the static test result data, to check the rate dependency of the particular SEA brace system. The adopted model, based on Graesser and Cozzarelli [35], is a uniaxial rate-independent hysteretic model, which is an extension of a rate-independent model for hysteretic behavior by Ozdemir [36]. The one-dimensional relationship between the stress, $\sigma$ and the strain, $\varepsilon$ for SEAs can be expressed as follows:

$$
\begin{gathered}
\dot{\sigma}=E \cdot\left[\dot{\varepsilon}-\left.|\dot{\varepsilon}| \cdot\left(\frac{\sigma-\beta}{Y}\right)^{n}\right|_{\rfloor}\right. \\
\beta=E \cdot \alpha \cdot\left\{\varepsilon^{\text {in }}+f_{\mathrm{T}} \cdot|\varepsilon|^{\lambda} \cdot \operatorname{erf}(a \cdot \varepsilon) \cdot[u(-\varepsilon \cdot \dot{\varepsilon})]\right\}
\end{gathered}
$$

where $\beta$ is the back stress, $E$ is the elastic modulus of the austenite phase, $Y$ is the yield stress or the transformation stress from the austenite to the martensite phases, $n$ is the overstress power controlling the sharpness of the transition from the elastic to the post-yield states. A constant $\alpha=E_{\mathrm{y}} /\left(E-E_{\mathrm{y}}\right)$ controls the post-yield slope of the $\sigma-\varepsilon$ curve, where $E_{\mathrm{y}}$ is the slope after yielding. The superimposed dot represents the ordinary time derivative. The material constants $f_{\mathrm{T}}$, $\lambda$ and $a$ control the recovery of the inelastic strain during unloading. Here, $\varepsilon^{\text {in }}=\varepsilon-\sigma / E$ is the inelastic strain. The error function, $\operatorname{erf}(x)$ and the unit step function $u(x)$ are mathematically defined as:

$$
\operatorname{erf}(x)=\frac{2}{\sqrt{\pi}} \cdot \int_{0}^{x} e^{-t^{2}} \mathrm{~d} t
$$




$$
u(x)=\left[\begin{array}{ll}
1 & x \geq 0 \\
0 & x<0
\end{array}\right]
$$

An optimization technique is used to determine all of the above material parameters, to fit the response from the quasi-static loading tests as reported later in Sections 4.1 and 4.2.

\subsection{SDOF modeling of frame response}

The whole frame model structure can be idealized as a SDOF system as shown in Figure 7. The dynamic response of the model is governed by the following equation of motion

$$
m \ddot{x}(t)+c \dot{x}(t)+F_{\mathrm{SEA}}(t)=-m \ddot{x}_{\mathrm{g}}(t),
$$

where $m$ is the mass attached at the top of the frame, $c$ is the damping coefficient, and $F_{\operatorname{SEA}}(t)$ is the restoring force, $x(t)$ is the displacement relative to the ground, and $\ddot{x}_{\mathrm{g}}(t)$ is the ground acceleration. Total of 400kg of lumped mass (mass of top steel plate including attachment members) is used, and the damping ratio was set to $3 \%$ with respect to the initial elastic stiffness of static test results. The restoring force $F_{\mathrm{SEA}}(t)$ is defined by proper material parameters for SEAs as written below.

The actual brace system has three pin bearing connections with steel and SEA bars of varying cross-sections. The proposed SDOF model is generalized to represent the whole brace with a single SEA brace element. The SEA hysteresis proposed by Graesser and Cozzarelli is adopted and subsequently modified to represent the resisting force versus drift angle hysteresis. The material parameters are optimized to the results obtained from the static test, resisting force versus drift angle plot. Additionally, a non-symmetric model is used to represent the response in positive and negative loading cycle. The corresponding physical quantities, stress $\sigma$, strain $\varepsilon$, and elastic modulus $E$ for a SEA element in Equations (1) and (2) are replaced by physical quantities, $F_{\text {SEA }}, \theta$ and $K_{\theta}$ representing the force-drift hysteresis for the whole brace as below:

$$
\begin{aligned}
& \dot{F}_{\mathrm{SEA}}=\left\{\begin{array}{l}
K_{\theta} \cdot\left[\dot{\theta}-|\dot{\theta}| \cdot\left(\frac{F_{\mathrm{SEA}}-\beta}{F_{\mathrm{Y}_{1}}}\right)^{n_{1}}\right\rfloor \\
K_{\theta} \cdot\left[\dot{\theta}-|\dot{\theta}| \cdot\left(\frac{F_{\mathrm{SEA}}-\beta}{F_{\mathrm{Y}_{2}}}\right)^{n_{2}}\right\rceil
\end{array}\right. \\
& \beta=\left\{\begin{array}{lc}
K_{\theta} \cdot \alpha_{1} \cdot\left\{\theta^{\text {in }}+f_{\mathrm{T}_{1}} \cdot \operatorname{erf}\left(a_{1} \cdot \theta\right) \cdot[u(-\theta \cdot \dot{\theta})]\right\} & (\theta>0) \\
K_{\theta} \cdot \alpha_{2} \cdot\left\{\theta^{\text {in }}+f_{\mathrm{T}_{2}} \cdot \operatorname{erf}\left(a_{2} \cdot \theta\right) \cdot[u(-\theta \cdot \dot{\theta})]\right\} & \text { (Otherwise) }
\end{array}\right.
\end{aligned}
$$

Here, subscripts 1 and 2 for the physical quantities and the constants, $F_{\mathrm{Y}}, \alpha, n, a$ and $f_{\mathrm{T}}$ represent the values for the positive and negative loading cycles in the non-symmetric SEA model adopted. It should be noted that the term with constant $\lambda$ in Equation (2) is omitted from Equation (7). The reason is that, after optimization, the value of $\lambda$ obtained was very small, making the term $|\varepsilon|^{\lambda}$ a unit value, as generalized in Equation (7). 


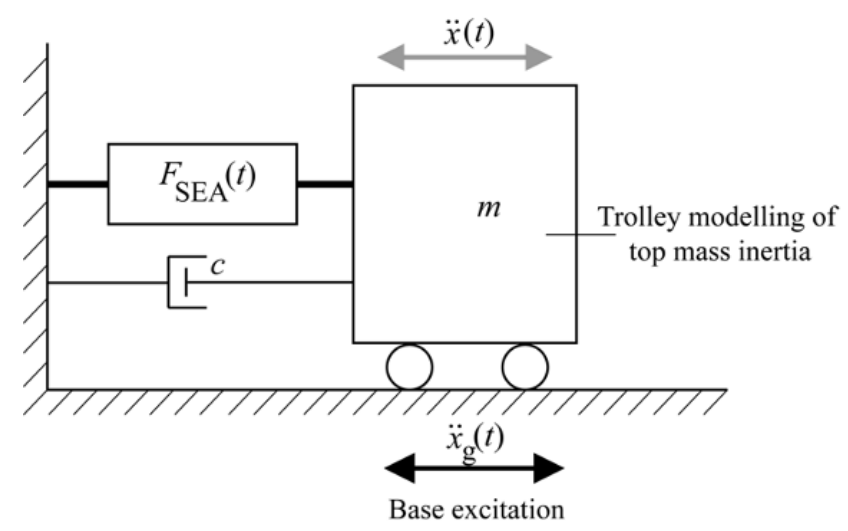

Figure 7. Idealized non-linear single-degree-of-freedom (SDOF) model.

\section{RESULTS AND DISCUSSIONS}

\subsection{Static results}

Figure 8 shows the results of the static test. Figure 8(a) shows the brace axial force computed from the strain gauge measurement (attached to the reduced section of the steel bar) versus the drift angle during the cyclic loading. The positive values for the bracing force represent the tensile force and the negative values characterize the compressive force in the braces. It is clear that for each cycle of loading, either positive or negative, only one brace works in tension and the three pin bearings in the other brace prevent any compression during the loading cycle.

Figure 8(b) shows the relationship between the restoring force and the relative drift angle of the frame. Test results for the resisting force are computed from the strain gauge measurement. A nonlinear least squares fit approach [37] was incorporated to optimize and approximate the material parameters in the SDOF model for Equations (6) and (7), calibrated to the static experimental restoring force versus the relative drift angle plot. An upper and lower bound constrained optimization programming [37] was adopted with interior-point optimization algorithm, with stopping criteria at maximum 1000 iterations. In order to fit the experimental response in the small deformation range, an additional input argument was passed on through function argument option [37], with the error function weighted in the small deformation region at the drift angle less than 1/1000radian. The optimized numerical hysteresis is shown in Figure 8(b) with the corresponding parameters: $K_{\theta}=793.15 \mathrm{kN} / \mathrm{rad}, F_{\mathrm{Y}_{1}}=1.49 \mathrm{kN}, \quad F_{\mathrm{Y}_{2}}=1.56 \mathrm{kN}, \alpha_{1}=0.125, \alpha_{2}=0.075, n_{1}=4, n_{2}$ $=1.62, a_{1}=795, a_{2}=642, f_{\mathrm{T} 1}=0.023$, and $f_{\mathrm{T} 2}=0.037$. Here, the restoring force versus the drift angle plot shows a typical flag-shape hysteresis for a SEA braced frame. The yield resistance was $1.28 \mathrm{kN}$ and the elastic stiffness was $0.66 \mathrm{kN} / \mathrm{mm}$ in the positive cycle, and, in the negative cycle, the yield resistance was $1.1 \mathrm{kN}$ and the stiffness was $0.55 \mathrm{kN} / \mathrm{mm}$. The yield resistance was computed for the resisting force computed from strain gauge measurement by applying the concept of the offset stress at $0.2 \%$ proof stress on the measurements recorded. 


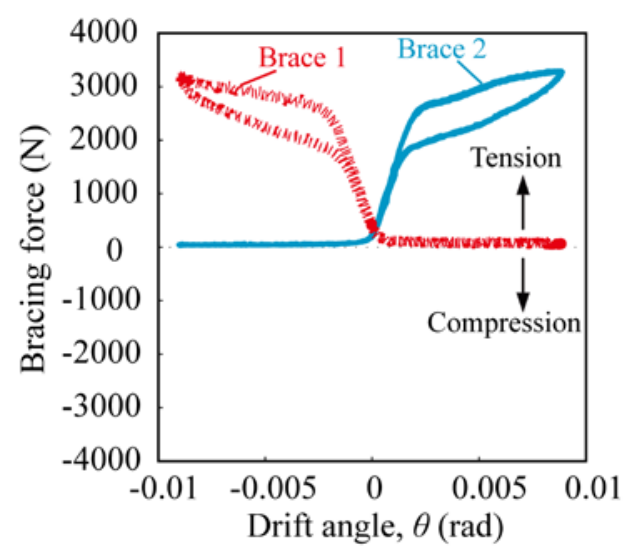

(a)

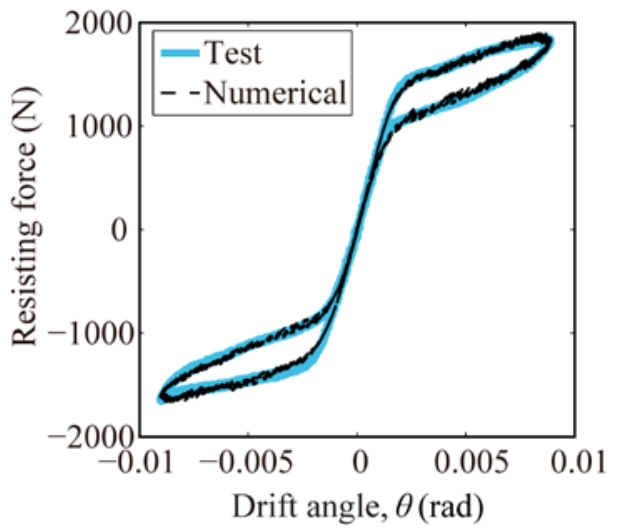

(b)

Figure 8. Static test results: (a) Brace force versus drift angle (Test), and (b) Resisting force versus drift angle (Test and numerical).

\subsection{Dynamic results}

Dynamic test results are shown in Figures 9 to 12. For numerical simulations, an average acceleration method [38] was used for the dynamic non-linear time-history analysis. The time step of $1 / 5000$ sec was adopted. Satisfaction of the equation of motion was checked at each time step with the tolerance value set for the residual force at $1 / 10000 \mathrm{~N}$.

Figure 9 shows the peak drift angles and the peak response acceleration (PRA) recorded for each excitation runs. There was negligible residual drift, $\theta_{\text {residual }}$ observed as shown in Figure 9(a). The maximum drift angle gradually increased with increasing the base excitation with the maximum ductility ratio value of 3.7 at the PGD of 4mm (RUN8). Here the ductility ratio for the given drift angle was computed as the ratio of the maximum drift angle to the yield drift angle, with the yield drift angle given by the ratio of yield resistance to the elastic stiffness obtained from the quasi-static test result. Both the maximum and residual drift angles are predicted well by the numerical model as shown in Figure 9(a). Figure 9(b) shows the peak ground acceleration (PGA) and the peak response acceleration (PRA) at the top for each excitation runs. For RUN8, the recorded PGA was $0.6 \mathrm{~g}$ and the PRA at the top of the frame system was reduced to $0.45 g$, nearly $75 \%$ of the PGA; where $g$ represents the gravity acceleration. Figure 9(b) shows the predicted PRA for the numerical model around $0.4 \mathrm{~g}$, in good agreement with the test observations. This clearly shows that the proposed SEA used brace frame system performed well in providing ductility and recentering capability to the structure as well as in reducing the response acceleration of the structure when subjected to large ground motions.

Figure 10 shows the experimental maximum strain values recorded for the SEA bars and the steel bars during each excitation runs. Figure 10(a) shows that the maximum strain values recorded for both the SEA bars were around 2.6\%. The maximum ductility ratio value of around 3.8 was recorded for the SEA bars. Here, the ductility ratio for the SEA bars was computed from the ratio of the maximum strain recorded to the yield strain of the SEA bar. The yield strain of the SEA bar was obtained from the material test shown in Figure 4. The ductility ratio values computed from the frame drift angle and the strain measurements of SEA bar agree reasonably well. Next, Figure 10(b) shows the maximum strain recorded in the steel bar (with strain gauge attached to the reduced section of steel bar as shown in Figure 5). The maximum strain in the steel bar reached up to 0.09\% which was within the elastic strain limit for steel bar used, taking nominal yield stress of 200MPa. 
(a)

Figure 9. Results for dynamic tests: (a) Drift angle, $\theta$ and ductility ratio, $\mu$, and (b) Peak ground acceleration (PGA) and peak response acceleration (PRA).

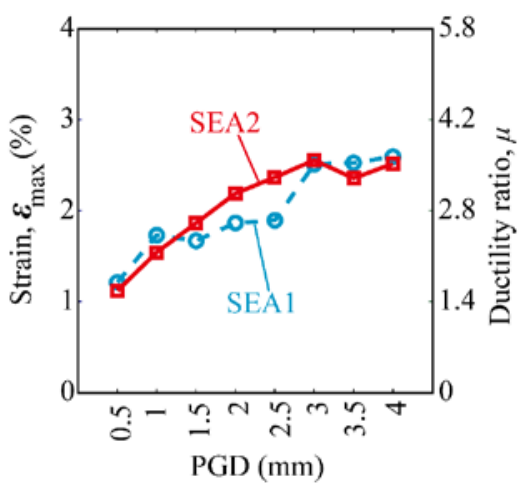

(a)

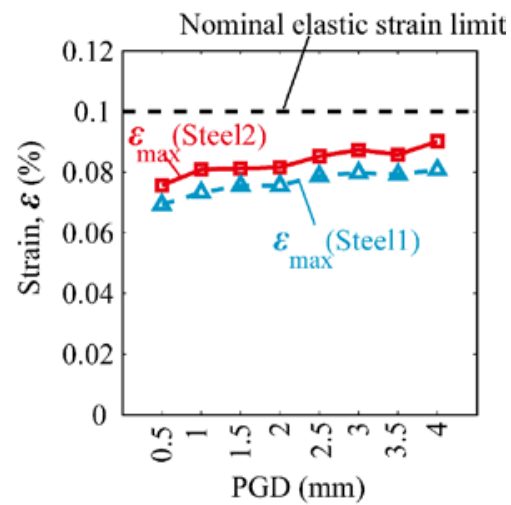

(b)

Figure 10. Results for dynamic tests: (a) Maximum strain on SEA bars, $\varepsilon$ and ductility ratio, $\mu$, and (b) Maximum strain on steel bars.

Figure 11 illustrates the comparison on the predicted time histories for the drift angle (left) and the top response acceleration (right). The analysis results on selected excitation runs (RUN2, RUN4, RUN6, RUN8) are presented. The drift time histories for each excitation runs (left figures in Figure 11) show no residual drifts at the end of each loading cycle, a typical characteristic behavior of the SEA brace frame system. The acceleration time histories show the maximum top response acceleration around $0.4 \mathrm{~g}$, which clearly showed effectiveness of the proposed SEA brace system in reducing/controlling the response acceleration, irrespective of the level of the base excitation. The proposed numerical model's response is in good agreement with the experimental observations, in following the response time history during as well as after the excitation (in free vibration state). The adopted damping ratio of $3 \%$ predicted the free vibration decay reasonably well for all the excitation runs. It should be noted that, there is some discrepancy on the test observation for free vibration response of RUN4 in free vibration, primarily contributed by variability in the pretensioning prior to the test. Clearly, the dynamic responses of the brace system are predicted well from the SEA material parameters calibrated from the quasi-static test. Figure 12 shows the comparison of the top response acceleration hystereses which illustrate typical flag-shape hystereses of SEA brace system. Similar to the experimental observation, at RUN2, the SEA bar just starts to yield, shown by the slight plateau in the acceleration-drift hysteresis. The subsequent excitation runs show larger plateau region, with SEA bars showing superelastic property through the flag-shape hystereses.

The results show reasonably close approximation of the experimental dynamic test results by the present SDOF model, calibrated from the quasi-static test. Such simple and straightforward 
representation of the dynamic experimental results by the numerical model based on the static test clearly demonstrates the negligible rate dependence of the proposed SEA brace frame system. Furthermore, both the test results and the numerical approximations reiterate the robustness and the effectiveness of the proposed brace frame system in terms of providing recentering capability to the frame system and reducing peak response acceleration within the base shear capacity, at loading frequencies up to $6 \mathrm{~Hz}$. It should be noted that fatigue characteristics and deterioration of hysteresis loops of SEAs in subsequent loading cycles are one of the major topics that need to be addressed for practical application of the proposed tension brace system as reported by recent studies $[13,39,40]$. Such fatigue properties of Cu-Al-Mn SEAs will be addressed in the authors' future works.

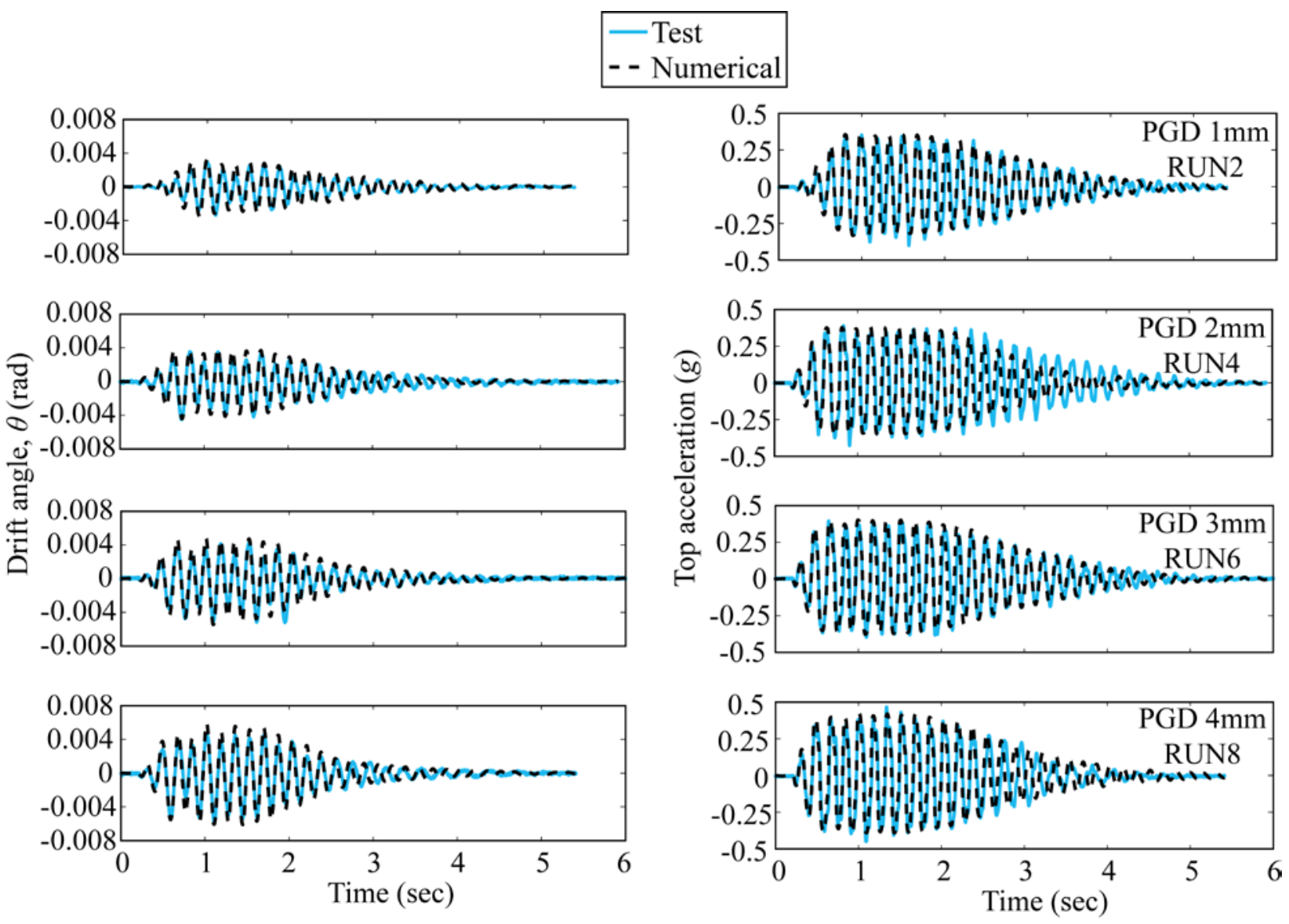

Figure 11. Comparison on experimental observations and numerical approximations for: drift time histories (left), and top acceleration time histories (right). 
Figure 12. Comparison on top response acceleration hystereses between experimental and numerical results.

\section{CONCLUSIONS}

Experimental and analytical works were done to investigate the feasibility of the use of Cu-Al-Mn SEA bars in tension braces in steel frame structures. These newly developed Cu-Al-Mn SEAs possess superelastic performance comparable to more popular Ni-Ti SEAs and also have high machinability, cold workability and are cost-effective to Ni-Ti. Ni-Ti SEAs also have relatively large rate dependence, non-negligible in the design of seismic devices. The present study concentrates to justify effectiveness of these $\mathrm{Cu}-\mathrm{Al}-\mathrm{Mn}$ SEAs as recentering brace system and also their negligible rate dependency to high frequency excitations.

Quasi-static and dynamic tests were done on 1/3 scaled single story single bay steel frame. Dynamic tests were performed at the loading frequency of $6 \mathrm{~Hz}$ to examine the rate dependence of $\mathrm{Cu}-\mathrm{Al}-\mathrm{Mn}$ SEAs and their possible application towards seismic engineering. These tests clearly showed that the present SEA brace system effectively controls the behaviour of the whole steel frame, with strong recentering capability. The SEA bars showed no residual strain at the end of each loading cycle. The tests demonstrated that pinching can be effectively avoided by the present tension braces. The dynamic test results also demonstrate the capability of the present tension braces in reducing the peak response acceleration within the base shear capacity.

A simplified SDOF analytical model is constructed to predict the response of SEA braced steel frame structure. The engineering parameters identified for Graesser and Cozzarelli model effectively matches the flag shaped hysteresis response of SEA. Moreover, the developed SDOF model based on a uniaxial rate-independent hysteretic model, calibrated from the quasi-static test 
closely represented the experimentally observed dynamic time histories. The results showed that the rate dependence of the $\mathrm{Cu}-\mathrm{Al}-\mathrm{Mn}$ SEAs is negligible up to the loading frequency of $6 \mathrm{~Hz}$. Such rate independence to loading rates demonstrates the strong potential of $\mathrm{Cu}-\mathrm{Al}-\mathrm{Mn}$ SEAs towards practical seismic applications. However, it should be noted that the tests reported in this paper are performed on a reduce-scaled structural configuration and subsequent practical application of these $\mathrm{Cu}-\mathrm{Al}-\mathrm{Mn}$ SEA bars would require larger size diameter SEA bars, which is under development at the moment.

\section{ACKNOWLEDGEMENTS}

The authors acknowledge the supports provided by the Japan Society of Seismic Isolation. The present research was also supported by the A-STEP program (\#AS2315014C) provided by Japan Science and Technology Agency (JST). Mr. Nobutoshi Yoshida, a technical researcher of Kyoto University, helped to conduct the experiments.

\section{REFERENCES}

1. Tremblay R, Filiatrault A. Seismic impact loading in inelastic tension-only concentrically braced steel frames: myth or reality? Earthquake Engineering and Structural Dynamics 1996; 25(12):1373-1389.

2. Phocas MC, Pocanschi A. Steel frames with bracing mechanism and hysteretic dampers. Earthquake Engineering and Structural Dynamics 2003; 32(5):811-825.

3. Filiatrault A, Tremblay R. Design of tension-only concentrically braced steel frames for seismic induced impact loading. Engineering Structures 1998; 20(12):1087-1096.

4. Kurata M, Leon R, DesRoches R. Rapid seismic rehabilitation strategy: Concept and testing of cable bracing with couples resisting damper. Journal of Structural Engineering ASCE 2012; 138(3):354-362.

5. Dolce M, Cardone D, Marnetto R. Implementation and testing of passive control devices based on shape memory alloys. Earthquake Engineering and Structural Dynamics 2000; 29(7):945-968.

6. Baratta A, Corbi O. On the dynamic behaviour of elastic-plastic structures equipped with pseudoelastic SMA reinforcements. Computational Materials Science 2002; 25:1-13.

7. Han Y, Li QS, Li A, Leung AYT, Lin P. Structural vibration control by shape memory alloy damper. Earthquake Engineering and Structural Dynamics 2003; 32(3):483-494.

8. McCormick J, DesRoches R, Fugazza D, Auricchio F. Seismic vibration control using superelastic shape memory alloys. Journal of Engineering Materials and Technology 2006; 128(3):294-301.

9. Adrawes B, DesRoches R. Effect of hysteretic properties of superelastic shape memory alloys on the seismic performance of structures. Structural Control and Health Monitoring 2007; 14(2):301-320.

10. Motahari SA, Ghassemieh M, Abolmaali SA. Implementation of shape memory alloy dampers for passive control of structures subjected to seismic excitations. Journal of Constructional Steel Research 2007; 63(12):1570-1579.

11. Casciati S, Faravelli L. Structural components in shape memory alloy for localized energy dissipation. Computers and Structures 2008; 86:330-339.

12. Torra V, Isalgue A, Lovey FC, Carreras G, Casciati F, Soul H. Experimental study of damping in civil engineering structures using smart materials (CuAlBe - SMA). An application to a steel 
portico. International Review of Mechanical Engineering 2010; 4(5):586-593.

13. Carreras G, Casciati F, Casciati S, Isalgue A, Marzi A, Torra V. Fatigue laboratory tests toward the design of SMA portico-braces. Smart Structures and Systems 2011; 7(1):41-57.

14. Yang CW, DesRoches R, Leon RT. Design and analysis of braced frames with shape memory alloy and energy-absorbing hybrid devices. Engineering Structures 2010; 32(2):498-507.

15. Asgarian B, Moradi S. Seismic response of steel braced frames with shape memory alloy braces. Journal of Constructional Steel Research 2011; 67(1):65-74.

16. Miller DJ, Fahnestock LA, Eatherton MR. Development and experimental validation of a nickel-titanium shape memory alloy self-centering buckling-restrained brace. Engineering Structures 2012; 40:288-298.

17. Xie Q. State of the art of buckling-restrained braces in asia. Journal of Constructional Steel Research 2005; 61(6):727-748.

18. Tsai KC, Hsiao PC, Wang KJ, Weng YT, Lin ML, Lin KC, Chen CH, Lai JW, Lin SL. Pseudo-dynamic tests of a full-scale CFT/BRB frame-Part I: Specimen design, experiment and analysis. Earthquake Engineering and Structural Dynamics 2008; 37(7):1081-1098.

19. Leon RT, Yang CS, Reinhorn A, Schachter M, Stojadinovic B, Yang T, Shing B, Wei Z. Results of early collaborative research on behavior of braced steel frames with innovative bracing schemes (zipper frames), The First International Conference on Advances in Experimental Structural Engineering, AESE, Nagoya, July 2005.

20. Schachter M, Reinhorn A. On the importance of 3-D analysis for zipper frames structures, Proceedings of the 8th U.S. National Conference on Earthquake Engineering, San Francisco, 18-22 April 2006.

21. Yang CS, Leon RT, DesRoches R. Cyclic behavior of zipper-braced frames. Earthquake Spectra 2010; 26(2):561-582.

22. Pasala DTR, Sarlis AA, Nagarajaiah S, Reinhorn AM, Constantinou MC, Taylor D. Adaptive negative stiffness: New structural modification approach for seismic protection. Journal of Structural Engineering ASCE 2013; 139(7):1112-1123.

23. Sarlis AA, Pasala DTR, Constantinou MC, Reinhorn AM, Nagarajaiah S, Taylor DP. Negative stiffness device for seismic protection of structures. Journal of Structural Engineering ASCE 2013; 139(7):1124-1133.

24. Casciati F, Faravelli L. Experimental characterisation of a Cu-based shape memory alloy toward its exploitation in passive control devices. Journal De Physique IV 2004; 115:299-306.

25. DesRoches R, McCormick JP, Delemont M. Cyclic properties of superelastic shape memory alloy wires and bars. Journal of Structural Engineering ASCE 2004; 130(1):38-46.

26. Nemat-Nasser S, Choi JY, Guo WG, Isaacs JB, Taya M. High strain-rate, small strain response of a NiTi shape-memory alloy. Journal of Engineering Materials and Technology 2005; 127(1):83-89.

27. Araki Y, Maekawa N, Omori T, Sutou Y, Kainuma R, Ishida K. Rate-dependent response of superelastic Cu-Al-Mn alloy rods to tensile cyclic loads. Smart Materials and Structures 2012; 21(3):032002. DOI: 10.1088/0964-1726/21/3/032002.

28. Araki Y, Endo T, Omori T, Sutou Y, Koetaka Y, Kainuma R, Ishida K. Potential of superelastic $\mathrm{Cu}-\mathrm{Al}-\mathrm{Mn}$ alloy bars for seismic applications. Earthquake Engineering and Structural Dynamics 2011; 40(1):107-115.

29. Sutou Y, Omori T, Kainuma R, Ishida K. Effect of grain size and texture on superelasticity of Cu-Al-Mn-based shape memory alloys. Journal De Physique IV 2003; 112:511-514.

30. Sutou Y, Omori T, Yamauchi K, Ono N, Kainuma R, Ishida K. Effect of grain size and texture on pseudoelasticity in $\mathrm{Cu}-\mathrm{Al}-\mathrm{Mn}$-based shape memory wire. Acta Materialia 2005; 
53(15):4121-4133.

31. Tanaka K. A thermomechanical sketch of shape memory effect: One-dimensional tensile behavior. Res Mechanica 1986; 18:251-263.

32. Achenbach M. A model for an alloy with shape memory. International Journal of Plasticity 1989; 5:371-395.

33. Liang C, Rogers CA. One-dimensional thermomechanical constitutive relations for shape memory materials, Journal of Intelligent Material Systems and Structures 1990; 1:207-234.

34. Lagoudas DC. Shape memory alloys: Modeling and Engineering Applications. Springer: New York, 2008.

35. Graesser EJ, Cozzarelli FA. Shape-memory alloys as new materials for aseismic isolation. Journal of Engineering Mechanics ASCE 1991; 117(11):2590-2608.

36. Ozdemir H. Nonlinear transient dynamic analysis of yielding structures. PhD Thesis, University of California, Berkeley, 1976.

37. MATLAB. Optimization ToolBox User's Guide Version 6.2.1. The Mathworks, Inc.: Natick, MA, 2012.

38. Chopra AK. Dynamics of Structures: Theory and Applications to Earthquake Engineering. Pearson Education: New Jersey, 2007.

39. Casciati S, Marzi A. Experimental studies on the fatigue life of shape memory alloy bars. Smart Structures and Systems 2010; 6(1):73-85.

40. Casciati S, Marzi A. Fatigue tests on SMA bars in span control. Engineering Structures 2011; 33(4):1232-1239. 